\title{
Análisis de la eficiencia de los estándares de transmisión de televisión digital por satélite en las bandas $\mathrm{Ku}$ y $\mathrm{Ka}$
}

\author{
Analysis of Standards Efficiency in Digital Television \\ Via Satellite at Ku and Ka Bands
}

\author{
Landeros-Ayala Salvador \\ Universidad Nacional Autónoma de México \\ Facultad de Ingeniería, División de Ingeniería Eléctrica \\ Departamento de Ingeniería de Telecomunicaciones \\ Correo:slander@unam.mx \\ Chávez-Cárdenas Sergio A. \\ Universidad Nacional Autónoma de México \\ Facultad de Ingeniería, División de Ingeniería Eléctrica \\ Departamento de Ingeniería de Telecomunicaciones \\ Correo:sergioachavez@gmail.com
}

\author{
González-Sánchez Juan C. \\ Universidad Nacional Autónoma de México \\ Facultad de Ingeniería, División de Ingeniería Eléctrica \\ Departamento de Ingeniería de Telecomunicaciones \\ Correo: juancarlosgs88@gmail.com
}

Información del artículo: recibido: agosto de 2011, aceptado: noviembre de 2012

\section{Resumen}

En este artículo se lleva a cabo un análisis de las principales características técnicas de los estándares para la transmisión de televisión digital por satélite. Con base en simulaciones y cálculo de enlaces se determina el estándar con mejor desempeño operativo y se realiza una comparación de la eficiencia para transmisiones en las bandas $\mathrm{Ku}$ y Ka con transpondedores transparentes y regenerativos, en términos de potencia, ancho de banda, tasa de información y margen del enlace, tanto a cielo despejado, como con lluvia en el enlace ascendente, en el descendente y en ambos.

\footnotetext{
Abstract

In this paper, an analysis on the main technical features of digital television standards for satellite transmission is carried out. Based on simulations and link budgets, the standard with the best operational performance is defined, based on simulations and link budget analysis, as well as a comparative efficiency analysis is conducted for the Ku and Ka bands for both transparent and regenerative transponders in terms of power, bandwidth, information rate and link margin, including clear sky, uplink rain, downlink rain and rain in both.
}

\section{Descriptores:}

- televisión digital

- satélite

- estándares

- transpondedor

- enlace

\section{Keywords:}

- digital television

- satellite

- standards

- transponder 


\section{Introducción}

Los sistemas de televisión digital son un conjunto de dispositivos que interactúan entre sí formando una cadena de transmisión y recepción. Resulta evidente pensar que si no existiese un conjunto de normas y formatos "estándares" para la transmisión de televisión, sería muy complicado visualizar contenidos entre las diversas regiones del mundo. La estandarización ha contribuido con la globalización y ha incentivado en el consumo de contenidos audiovisuales de mejor calidad. Esto entre otras cosas, hace que los medios de comunicación sean una industria altamente lucrativa y de vanguardia.

Desde el inicio de los sistemas de televisión, el desarrollo de estándares se ha dado bajo la influencia de potencias tecnológicas en bloques geográficos diferentes. En la actualidad, existen 4 estándares principales:

Digital video broadcasting (DVB): Es una organización encabezada por países del bloque europeo que en el caso de la televisión digital por satélite (DVB-S y DVBS2), se puede considerar como el estándar de facto. DVB está compuesto por más de 270 empresas e instituciones de todo el mundo.

Advanced television system committee (ATSC): Es el grupo que se encarga del desarrollo de estándares de televisión digital en Estados Unidos. En el caso de radiodifusión de televisión digital terrestre, ha sido adoptado por países vecinos como Canadá, México y algunos países de Centroamérica influenciados por este bloque. Para aplicaciones por satélite es ATSC A/81.
Integrated services digital broadcasting (ISDB): Es el estándar japonés para televisión y radio digitales. Su penetración ha aumentado debido a la adopción de Brasil, provocando que varios países de América del Sur repliquen la tendencia formando un tercer bloque geográfico. ISDB-S es para servicios satelitales.

Advanced broadcasting system (ABS-S): Desarrollado en China, con ventajas de desempeño respecto a DVB$S$ y con casi el mismo desempeño que DVS-S2, pero con menor complejidad. Todavía sin desarrollos comerciales.

En aplicaciones por satélite, con la creciente demanda de servicios, cada vez existe un mayor interés en desarrollar sistemas que tengan un mejor desempeño en el uso del segmento espacial, optimizando potencia y ancho de banda de los transpondedores.

\section{DVB-S}

DVB-S es la primera especificación de televisión por satélite aprobada por el ETSI con la denominación ETSI EN 300421 en el año de 1993. En este estándar se definen las características de la radiodifusión de televisión digital y datos a través de satélite FSS o BSS para la banda Ku. Permite la transmisión de varios programas de calidad estándar o HDTV a través de un multiplexor basado en la especificación MPEG-2.

Actualmente, el DVB-S también denominado Sistema A por la UIT (UIT-R, BO.1516(01.12), 2012) es utilizado en servicios de empresas como Dish Networks, Sky Brasil, Sky México, entre otros.

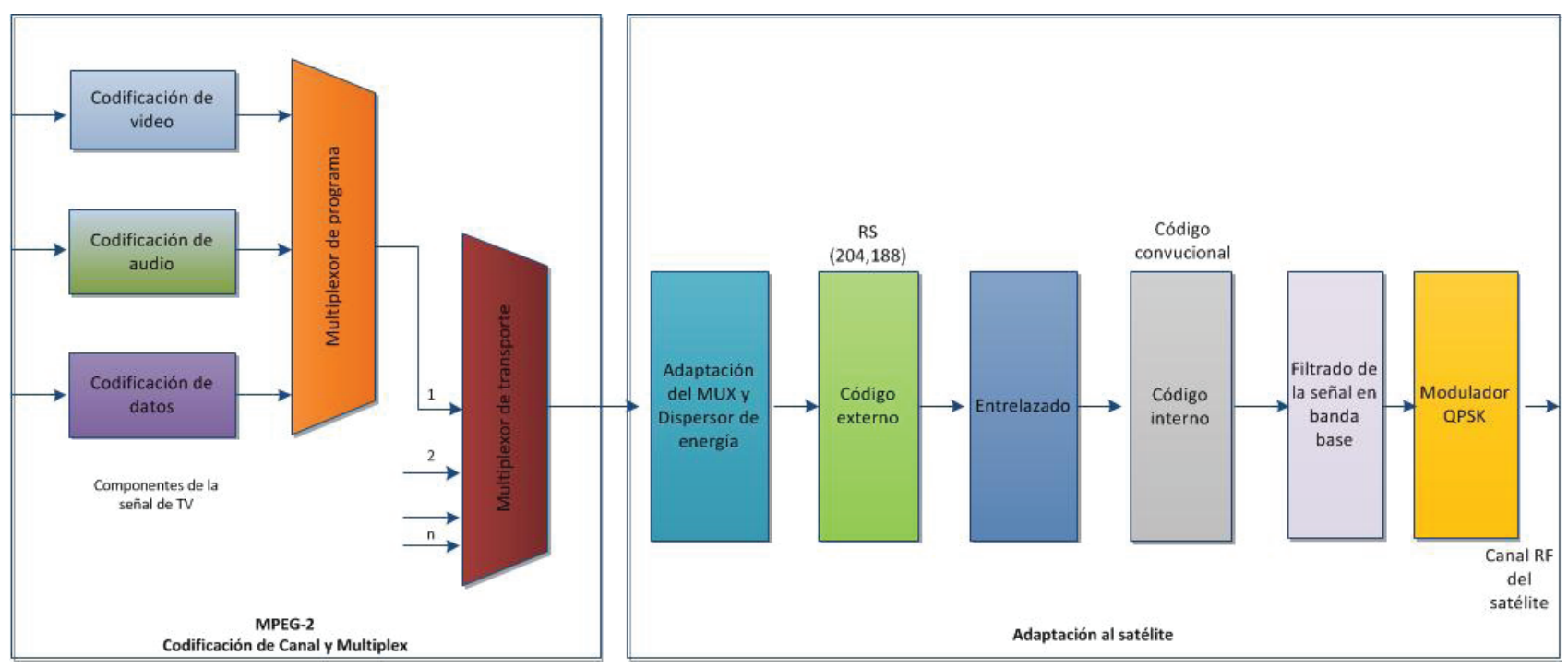

Figura1. Estándar DVB-S

Fuente: ETSI EN 300421 
El esquema funcional en bloques del transmisor para DVB-S se muestra en la figura 1. En el podemos apreciar que para la transmisión al satélite, las señales de audio y video digitales pasan por una etapa de codificación de canal y multiplexado. De esta etapa se obtiene una cadena de datos que son codificados contra errores y procesados digitalmente a señales moduladas de radiofrecuencia. Esta última etapa se conoce como adaptación al satélite.

\section{DVB-DSNG}

La UIT-R define DSNG (digital satellite news gathering) como una transmisión temporal u ocasional de noticias de televisión o audio para motivos de su radiodifusión, usando estaciones terrenas móviles con antenas transmisoras portátiles y transportables (UIT-R, SNG.770-1, 1994). El equipo debe ser capaz de transmitir el o los programas de video generados en el sitio. Opcionalmente, el sistema debería ser capaz de proveer interacción entre los dos sitios de comunicación. Otra característica de este sistema es la facilidad de implementación del enlace con la mínima cantidad de equipo y personas en su manejo.

En la figura 2 se observan de manera funcional las características del estándar a la transmisión (EN 301 210, 1999). La diferencia con el estándar DVB-S reside en la posibilidad de utilizar diferentes modulaciones digitales en la etapa de adaptación al satélite. Un esquema de mayor jerarquía que QPSK reduce el consumo de ancho de banda en el canal satelital, no obstante puede comprometer mayor consumo de potencia en el satélite, la cual también es limitada.

\section{DVB-S2}

Los estándares de televisión por satélite han seguido una tendencia que engloba características de sus predecesores, tal es el caso de DVB-DSNG con DVB-S. Sin embargo, la principal limitación de estos sistemas está dada por la eficiencia de los códigos de protección contra errores en el canal y el algoritmo de compresión de los contenidos audiovisuales.

Las investigaciones en el campo de las comunicaciones digitales, particularmente en el área de técnicas de corrección de errores y la introducción de los códigos LDPC (Morello y Mignone, 2006), impulsaron nuevas innovaciones tecnológicas. Como resultado de esto, se lograron ofrecer servicios de mayor capacidad que llevaron a la DVB a definir en 2003 el estándar DVB-S2 (EN 302 307, 2009) como la segunda generación de servicios por satélite. Este nuevo estándar ya no está orientado solamente a la radiodifusión de TV por satélite, sino que se desarrolló de acuerdo a las tendencias de convergencia en los servicios audiovisuales y de datos.

Existen 3 aplicaciones diferentes para DVB-S2:

- Radiodifusión de televisión SDTV y HDTV.

- Servicios interactivos, incluyendo acceso a inter net, para aplicaciones de consumo.

- Distribución de contenidos de datos y servicios de Internet.

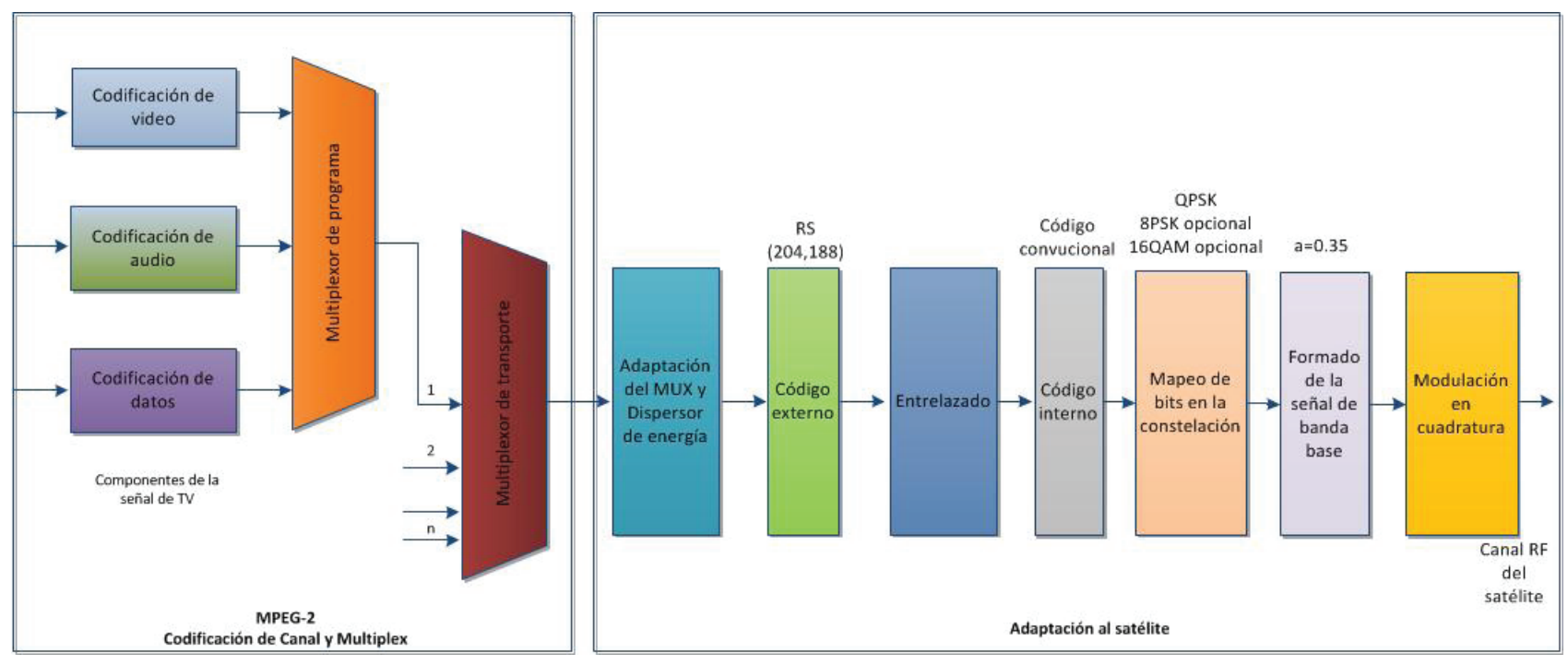

Figura 2. Estándar DVB-DSNG

Fuente: ETSI EN 301210 
El bloque funcional de un transmisor DVB-S2 es mucho más complejo que la primera generación (Morello y Mignone, 2006), se muestra en la figura 3. Al tratarse de un sistema que permite la transmisión de datos de diferente tipo, el estándar DVB-S2 incorpora una etapa de adaptación de la trama digital que incluye incorporación de datos de señalización y multiplexado. La adaptación al satélite por su parte, incorpora códigos de protección contra errores tipo LDPC y BCH que hacen más robusta la integridad de los datos. Además, se incorporan esquemas de modulación de mayor jerarquía que QPSK y se mejora la etapa de filtrado de la señal modulada. DVB-S2 también puede incorporar características adaptivas del canal en el caso de comunicación full-duplex, favoreciendo la disponibilidad del enlace por satélite.

En el caso de una señal de video para su radiodifusión, se utilizan los esquemas QPSK y 8PSK. Cuando se utiliza DVB-S2 en aplicaciones de video profesional (como DSGN), se pueden aplicar los esquemas 16APSK y 32APSK, cuya eficiencia espectral es mucho mayor, pero es necesario utilizar el transpondedor en una región de mayor linealidad en la transmisión. También, el consumo de potencia es superior comparado con esquemas de menor orden.

En la figura 4 se observan los diagramas de constelación que utiliza el estándar DVB-S2 (Morello y Mignone, 2006). Los esquemas 16APSK y 32APSK, podrían ser más susceptibles a errores a la recepción por la mayor dependencia con la amplitud de la señal y a la baja linealidad de los amplificadores de microondas.
El desempeño de los estándares de transmisión de TV por satélite se puede analizar con un gráfico que relacione los dos principales recursos con que cuenta un satélite de comunicaciones: ancho de banda y potencia. En la gráfica de la figura 5 se muestra el desempeño para DVB-S, DVB-DSNG Y DVB-S2 para un mismo BER de $10^{-7}$ y un programa de $5 \mathrm{Mbps}$ sobre un canal AWGN comparando la relación de portadora a ruido (nivel de potencia de la señal) con la eficiencia espectral (proporcional al ancho de banda) (Morello y Mignone, 2006).

En este caso, se observa que los esquemas manejados en DVB-S2 tienen una eficiencia de codificación cercana al límite teórico máximo (límite de Shannon). También se aprecia que se requiere un menor nivel de potencia en DVB-S2 comparado con la misma señal codificada en otro estándar con iguales niveles de calidad. Además, si el nivel de potencia es constante, la eficiencia espectral es mucho mayor para DVB-S2 que para DVB-S Y DVB-DSNG.

\section{ISDB-S}

ISDB (integrated services digital broadcasting) fue creado en Japón para las transmisiones de radio y televisión digital. Sustentado por la organización conocida como ARIB (association of radio industries and businesses) se crearon diferentes estándares libres.

En la figura 6, se muestra un diagrama de bloques de este sistema, en donde las principales diferencias con los de la ESTI están contenidas en el códec de audio

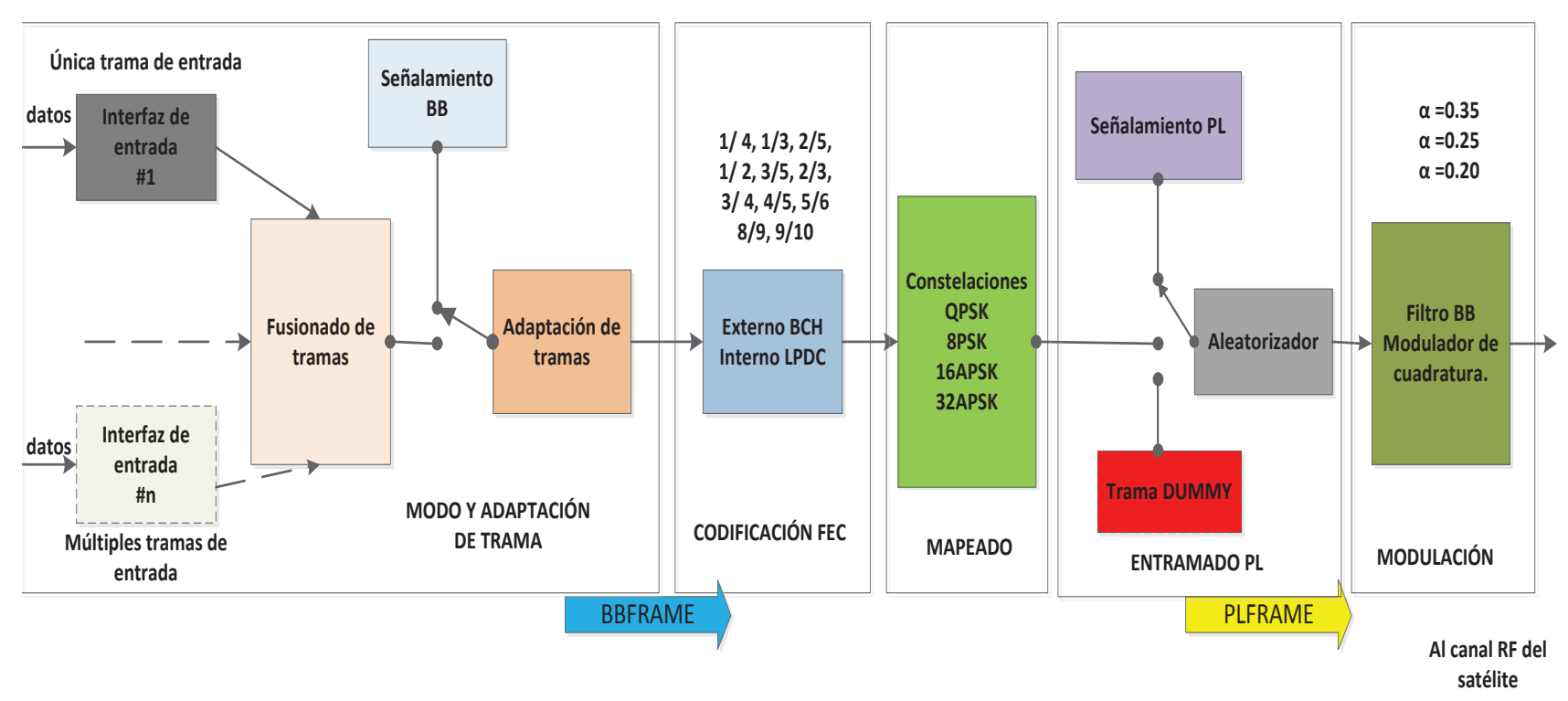

Figura 3. Estándar DVB-S2 

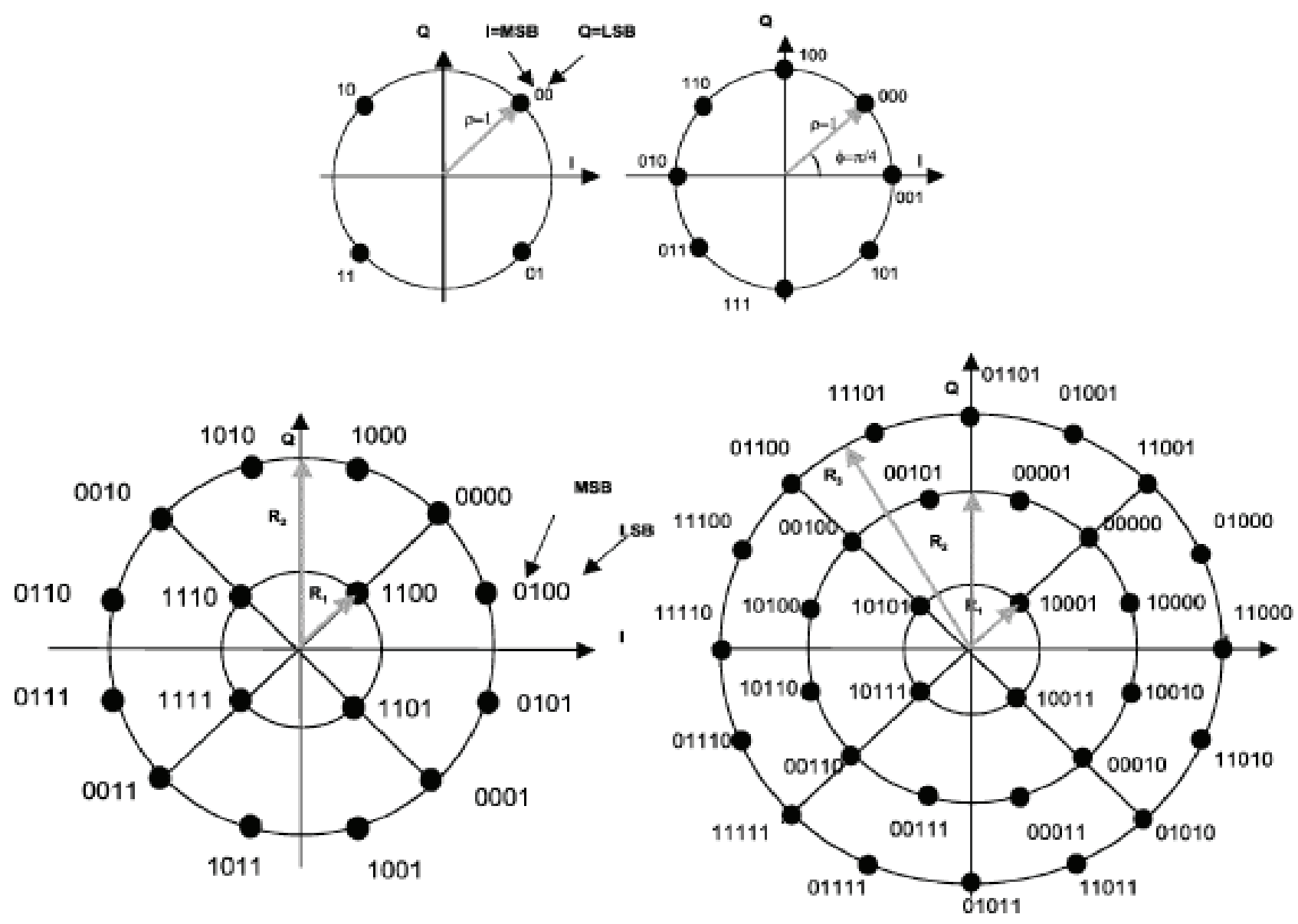

Figura 4. Esquemas de modulación del estándar DVB-S2

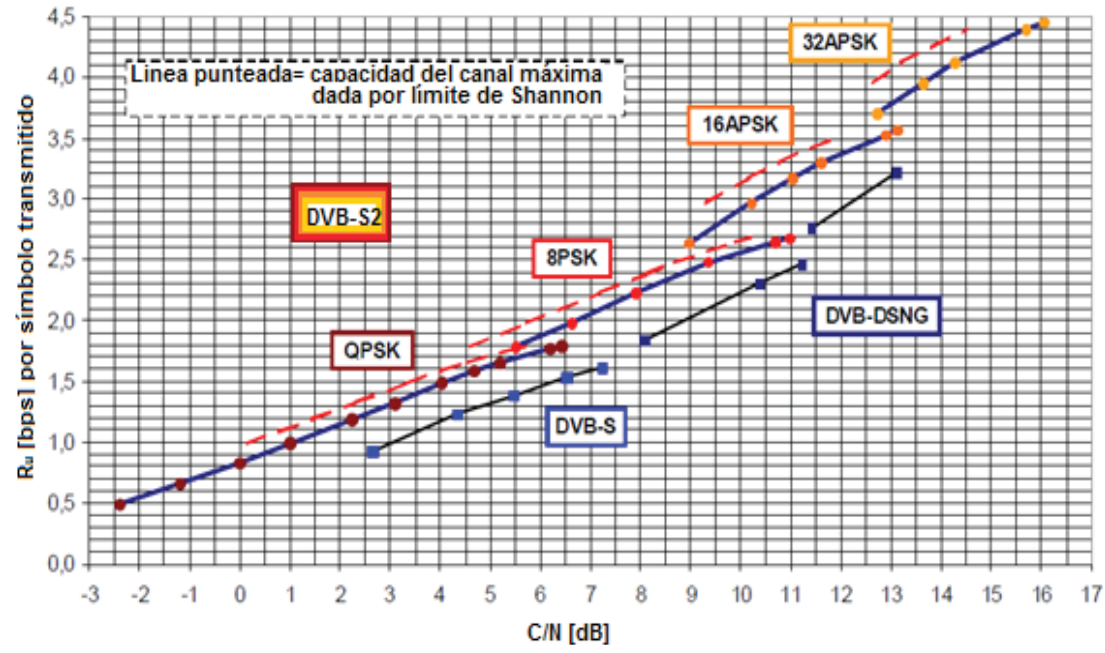

Figura 5. Desempeño de estándares de la familia DVB 


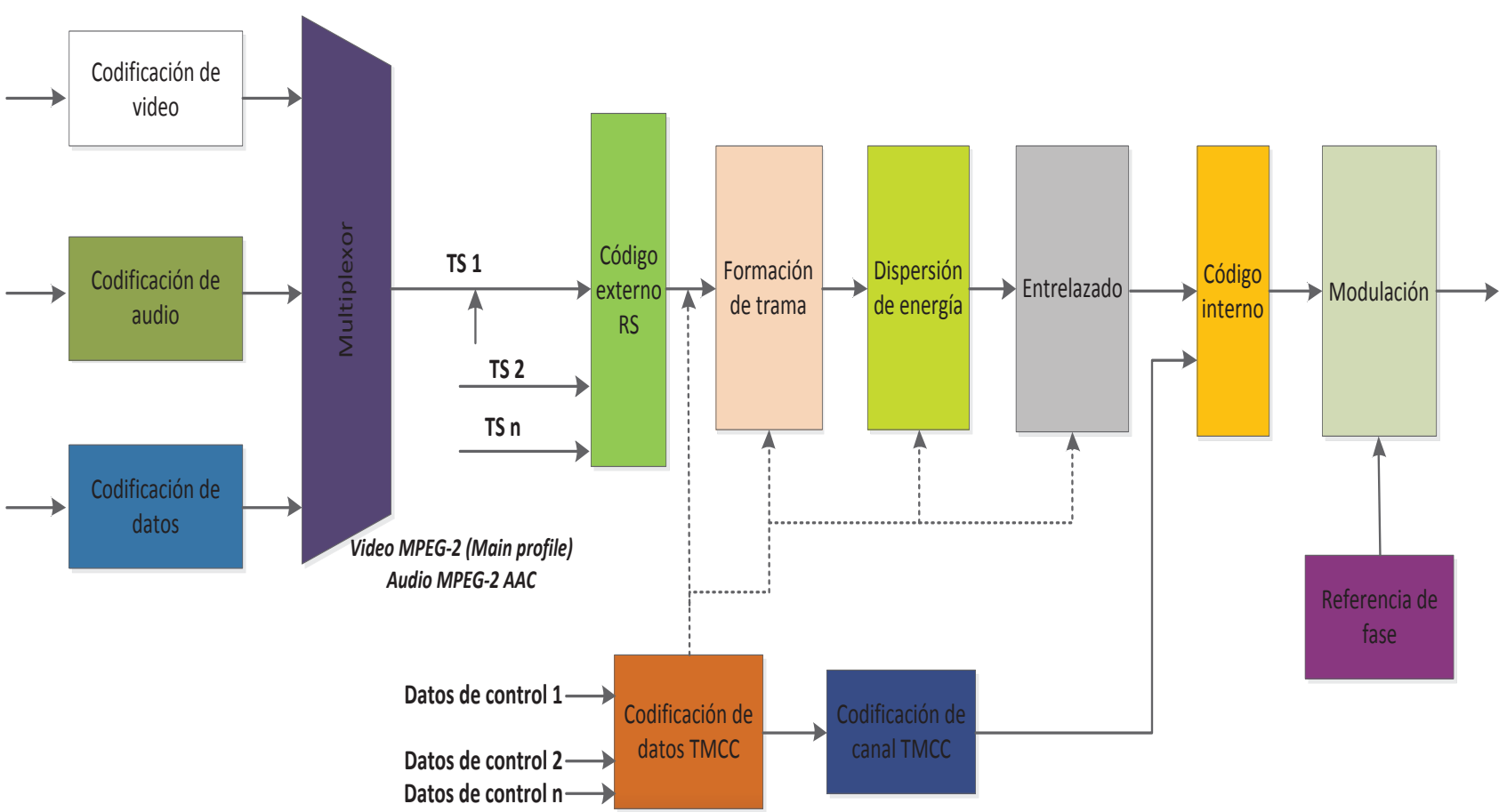

Figura 6. Estándar ISDB-S

Fuente: NHK STRL

y la etapa de procesamiento digital de la trama de datos para su transmisión al satélite (Saito et al., 2000).

De la misma manera que la norma europea DVB, ISDB cuenta con una gama de estándares dependiendo del medio de transmisión. Los más conocidos son el de televisión terrestre ISDB-T, el de televisión satelital ISDB-S y el de televisión por cable ISDB-C.

\section{ATSC A/81}

ATSC (advanced television systems committee) fue formado en el año 1982 por varias asociaciones Norteamericanas. En la actualidad está conformada por aproximadamente 140 miembros de sectores como la radiodifusión, equipos de transmisión, electrónica, cableado, servicios satelitales, semiconductores, entre otros.

Los estándares de televisión digital del consorcio ATSC incluyen señales de HDTV, SDTV, emisión de datos, audio multicanal y radiodifusión satelital DTH ( $d i-$ rect to home).

El sistema comprende dos partes: el sistema de transmisión y el receptor/decodificador. El sistema de transmisión comprende a un multiplexor de transporte, un modulador y una etapa de codificación. Las especificaciones para el modulador y la etapa de codificación no fueron vistas como necesarias para los propósitos del estándar y se dejaron a elección del proveedor de servicios para su implementación. La figura 7 muestra un diagrama de bloques de este estándar.

En la práctica, este sistema nunca ha sido implementado debido al surgimiento posterior de DVB-S2. Por otro lado, ATSC A/81 no aporta mejoras sustanciales a la eficiencia comparándose con DVB-S por lo que desde un principio se encontró en un panorama complicado para su evolución.

\section{ABS-S}

Este sistema ha demostrado en pruebas de campo y de laboratorio un desempeño similar al DVB-S2 (Shi et al., 2008), con una complejidad menor (figura 8). El principio de funcionamiento y características son muy similares a su homólogo estandarizado por la ETSI.

Con la información recopilada sobre todos los estándares actuales de transmisión de TV por satélite se hicieron 2 tablas que resumen y comparan las características principales, necesarias para realizar un análisis de desempeño. La tabla 1 muestra una comparación de la tasa de transmisión entre ABS-S y DVB-S2 y en la tabla 2, se comparan los estándares principales (EN 300 421, 1997; EN 301 210, 1999; EN 302 307, 2009; Saito et al., 2000; Shi, et al., 2008). 

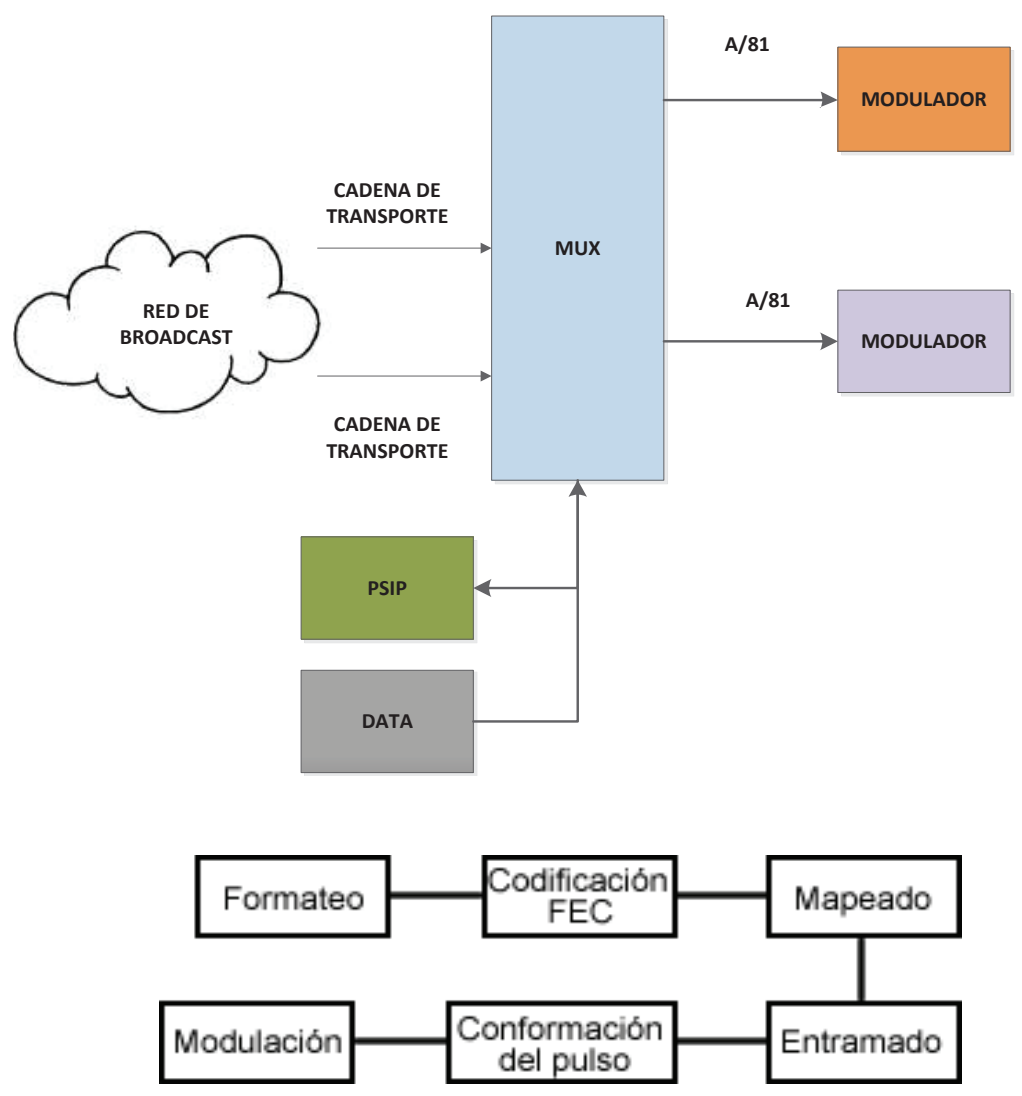

\begin{tabular}{cccccc}
\hline Modulación & FEC & Roll-off & Ancho de banda & $\begin{array}{c}\text { Tasa de datos } \\
\text { DVB-S2 (Mbps) }\end{array}$ & $\begin{array}{c}\text { Tasa de datos } \\
\text { ABS-S (Mbps) }\end{array}$ \\
\hline QPSK & $3 / 4$ & 0.2 & $20 \mathrm{MHz}$ & 29.75 & 29.53 \\
8 PSK & $2 / 3$ & 0.2 & $20 \mathrm{MHz}$ & 39.61 & 39.32 \\
\hline
\end{tabular}

Figura 7. Estándar ATSC

Figura 8. Estándar ABS-S

Tabla 1. Comparación ABS-S y DVB-S2

Tabla 2. Comparativa de los estándares principales

\begin{tabular}{|c|c|c|c|c|}
\hline Parámetro & DVB-S & DVB-S2 & ISDB-S & ABS-S \\
\hline Códec de video & MPEG-2 MP@ML & MPEG-2, MPEG-4 & MPEG-2 & MPEG \\
\hline Códec de audio & MPEG-1 Capa 2 & AAC, AC-3, MPEG-1 & MPEG-2 AAC & MPEG-1, AAC \\
\hline Multiplexaje & MPEG Transport Stream & $\begin{array}{c}\text { MPEG Transport Stream, } \\
\text { ATM, IP }\end{array}$ & MPEG Transport Stream & $\begin{array}{l}\text { MPEG Transport } \\
\text { Stream }\end{array}$ \\
\hline $\begin{array}{l}\text { Tamaño del paquete de } \\
\text { transporte }\end{array}$ & 188 bytes & $\begin{array}{l}\text { Variable dependiendo del } \\
\text { multiplexaje }\end{array}$ & 188 bytes & $\begin{array}{l}\text { Variable dependiendo } \\
\text { del multiplexaje }\end{array}$ \\
\hline Código externo & $\operatorname{RS}(204,188,8)$ & $\mathrm{BCH}$ variable & $\operatorname{RS}(204,188,8)$ & NO \\
\hline Código interno & $\begin{array}{c}\text { Convolucional (FEC: } 1 / 2,2 / 3, \\
3 / 4,5 / 6,7 / 8)\end{array}$ & $\begin{array}{c}\text { LDPC (FEC: } 1 / 4,1 / 3,2 / 5 \\
1 / 2,3 / 5,2 / 3,3 / 4,4 / 5 \\
5 / 6,8 / 9 \text { y } 9 / 10)\end{array}$ & $\begin{array}{l}\text { 8PSK: Trellis QPSK, } \\
\text { BPSK: Convolucional }\end{array}$ & LDPC (Varias). \\
\hline $\begin{array}{l}\text { Ancho de banda del } \\
\text { transpondedor }\end{array}$ & Hasta $54 \mathrm{MHz}$ & Variable & $36 \mathrm{MHz}$ & Variable \\
\hline Roll-Off & 0.35 (coseno elevado) & $\begin{array}{c}0.20,0.25,0.35 \\
\text { (coseno elevado) }\end{array}$ & 0.35 (coseno elevado) & $0.20,0.25,0.35$ \\
\hline Esquema de modulación & QPSK, BPSK(opcional) & $\begin{array}{c}\text { QPSK, 8PSK, 16APSK o } \\
\text { 32APSK }\end{array}$ & BPSK, QPSK, TC8PSK & $\begin{array}{l}\text { QPSK, 8PSK, 16APSK, } \\
\text { 32APSK }\end{array}$ \\
\hline Symbol Rate & 1 a $45 \mathrm{Ms} / \mathrm{s}$ (promedio) & Variable & $28.86 \mathrm{Ms} / \mathrm{s}$ & Variable \\
\hline
\end{tabular}




\section{Análisis de la eficiencia los de los estándares de transmisión de TV por satélite}

Existen diversas formas para comparar la eficiencia de un sistema de comunicaciones por satélite. En el caso de la transmisión de video por satélite existen diversos parámetros importantes:

- Tasa de datos binaria. Es la cantidad máxima de datos que se puede trasmitir por el canal limitado en ancho de banda. Mientras esta tasa sea mayor, es evidente que se puede transmitir más información. Esto repercute en mejoras en la calidad del audio y del video.

- Ancho de banda disponible. Al ser los satélites canales limitados en ancho de banda, es necesario tomar en cuenta la disponibilidad de éste. Si se dispone de un transpondedor completo para la transmisión de la información, se aprovecha el máximo la potencia disponible. En cambio, si el transpondedor es compartido con otros servicios, es necesario balancear la potencia y ancho de banda entre todas las portadoras.

- $E b / N_{0}$. Parámetro que nos permite comparar si la señal recibida tiene la suficiente calidad para ser decodificada en el receptor de acuerdo a las características acordadas en el estándar de transmisión. Con un $\mathrm{Eb} /$ No mayor al de umbral, se tiene un margen que asegura la correcta transmisión de los datos con una cantidad de errores aceptable.

- $C / N$. Similar al Eb/No, es posible obtener el umbral en el que se asegura que la potencia de la portadora es suficiente para lograr establecer el enlace.

Con base a estos parámetros, se pueden establecer dos categorías para evaluar la eficiencia de los estándares de transmisión:

1. Umbrales requeridos para transmitir la señal de TV (depende de la codificación de fuente).

2. Margen del enlace de la señal (referente al cálculo de los niveles necesarios para que el enlace se lleve a cabo).

Para realizar este análisis, se debe de tomar en cuenta que los estándares para la transmisión de televisión digital por satélite presentados en este trabajo no son todos de características similares o se implementan en diferentes aplicaciones y regiones. De acuerdo a sus características y estado de uso, los estándares más convenientes para su análisis son:

- DVB-S/DVB-DSNG
- DVB-S2

- ISDB-S

Considerando que el ABS-S todavía se encuentra en una etapa incipiente.

\section{Eficiencia de codificación y ancho de banda}

Dependiendo del estándar ocupado en la codificación de fuente (MPEG-2 o MPEG-4/AVC), el rendimiento de la codificación en el caso de MPEG-4 puede ir de 43 a $63 \%$. Esto significa que se puede codificar aproximadamente el doble de información en MPEG-4/AVC, comparado con un flujo de datos codificados en MPEG-2.

En la etapa de codificación de canal, definida por los estándares de transmisión, el rendimiento máximo está cerca de 30\% para el caso de DVB-S2, comparado con DVB-S. A continuación algunos ejemplos comparativos.

\section{Sistema DTH con transpondedores de $36 \mathrm{MHz}$ y modulación QPSK}

Como condiciones de análisis, se establecieron los siguientes parámetros en todos los casos:

- Información codificada en MPEG-2.

- Tasa de símbolos: 26.667 MS/s.

- Esquema de Modulación: QPSK.

- FEC: $3 / 4$.

- Tasa de datos y de codificación constante para DVBS2 e ISDB-S.

- Roll-Off de 0.35 .

En la tabla 3 se muestra una comparación de los principales estándares en términos de tasa de información y potencia.

Tomando en cuenta los niveles de $\mathrm{Eb} / \mathrm{No}$ y $\mathrm{C} / \mathrm{N}$ requeridos por cada enlace, la superioridad de la corrección de errores en el estándar DVB-S2 permite el consumo de menos potencia, logrando así un enlace con niveles de calidad buenos y ocupando menos recursos. Bajo estas condiciones, se observa que en total se requieren 2.3 veces menos potencia a la recepción. No obstante que el ahorro de potencia es importante. Por otra parte, se observa que en el estándar ISDB-S los requerimientos de calidad son mayores y se requiere mayor potencia para tener una eficiencia similar a la del estándar DVB-S. Vale la pena mencionar que el estándar ISDB-S se aplica solamente en el territorio de Japón. 
Tabla 3. Comparación de los estándares en función de la tasa de información y de la potencia

\begin{tabular}{|c|c|c|c|c|c|c|}
\hline Estándar & $\begin{array}{c}\text { Tasa neta de } \\
\text { información } \\
(\mathrm{kbps})\end{array}$ & $\begin{array}{c}\text { Ancho de banda } \\
\text { requerido en el satélite } \\
(\mathrm{MHz})\end{array}$ & $\mathrm{Eb} / \mathrm{No}(\mathrm{dB})^{*}$ & $\mathrm{C} / \mathrm{N}(\mathrm{dB})$ & $\begin{array}{l}\text { rcentaje de eficiencia } \\
\text { en el volumen } \\
\text { de información } \\
\text { transmitida }(\%)^{* *}\end{array}$ & $\begin{array}{c}\text { Porcentaje de } \\
\text { potencia requerida a la } \\
\text { recepción }(\%)^{* *}\end{array}$ \\
\hline DVB-S /DVB-DSNG & 36853.8 & 36.0 & 6.26 & 6.37 & $100 \%$ & $100 \%$ \\
\hline DVB-S2 & 38723.2 & 36.0 & 2.41 & 2.73 & $105.1 \%$ & $43.3 \%$ \\
\hline ISDB-S & 36154.3 & 36.0 & 6.59 & 7.14 & $98.1 \%$ & $119.4 \%$ \\
\hline
\end{tabular}

*Para DVB-S/DVB-DSNG/DVB-S2: BER $=1 \times 10^{-7}$; para ISDB-S: $B E R=1 \times 10^{-11}$

** Cálculo comparativo tomando como referencia de comparación al estándar DVB-S

Tabla 4. Tasa de datos y codificación constante

\begin{tabular}{|c|c|c|c|c|c|c|}
\hline Estándar & $\begin{array}{c}\text { Tasa neta de } \\
\text { información } \\
(\mathrm{kbps})\end{array}$ & $\begin{array}{c}\text { Ancho de banda } \\
\text { requerido en el } \\
\text { satélite } \\
(\mathrm{MHz})\end{array}$ & $\mathrm{Eb} / \mathrm{No}(\mathrm{dB})$ & $\mathrm{C} / \mathrm{N}(\mathrm{dB})$ & $\begin{array}{l}\text { Porcentaje de } \\
\text { eficiencia en } \\
\text { el volumen de } \\
\text { información } \\
\text { transmitida (\%) }\end{array}$ & $\begin{array}{c}\text { Porcentaje de } \\
\text { potencia requerida a la } \\
\text { recepción }(\%)\end{array}$ \\
\hline$D V B-S$ & 43013.3 & 36.0 & 7.53 & 8.31 & $100 \%$ & $100 \%$ \\
\hline$D V B-S 2$ & 69762.2 & 36.0 & 5.51 & 8.38 & $162.2 \%$ & $101.6 \%$ \\
\hline$I S D B-S$ & 42179.4 & 36.0 & 7.26 & 8.48 & $98.1 \%$ & $104.0 \%$ \\
\hline
\end{tabular}

Por tal motivo, los satélites utilizados para cubrir la geografía de las islas pueden contar, entre muchas otras ventajas, con coberturas regionales con altos niveles de ganancia y potencia radiada. Adicionalmente, es importante recordar que ISDB-S adopta técnicas de modulación variable en la implementación real. Con esto, la disponibilidad es alta y los datos se transmiten de manera confiable.

La eficiencia buscada se alcanza variando los parámetros de transmisión y adecuando estos niveles a los niveles que puede proporcionar el satélite.

Sistema DTH con transpondedores de $36 \mathrm{MHz}$ y parámetros ajustados a una relación $\mathrm{C} / \mathrm{N}$ similar:

- Información codificada en MPEG-2.

- Tasa de símbolos DVB-S @ $\alpha=0.35: 26.667 \mathrm{MS} / \mathrm{s}$.

- Tasa de símbolos DVB-S2 @ $\alpha=0.25: 28.80 \mathrm{MS} / \mathrm{s}$.

- Tasa de símbolos ISDB-S @ $\alpha=0.35: 26.667 \mathrm{MS} / \mathrm{s}$.

- Esquema DVB-S: QPSK 7/8.

- $\quad$ Esquema DVB-S2: 8QPSK 5/6.

- Esquema ISDB-S: QPSK 7/8.

En la tabla 4 se comparan los estándares con tasa de datos y codificación constante para DVB-S2 e ISDB-S. De esta tabla 4 podemos obtener varios resultados:

- Si se ajusta el esquema de codificación de tal manera que se tenga un umbral de $\mathrm{C} / \mathrm{N}$ similar en todos los casos, se observa que el estándar DVB-S2 puede au- mentar la cantidad de información más de 60\%, comparado con DVB-S e ISDB-S.

- DVB-S e ISDB-S tienen un desempeño muy similar; sin embargo, los márgenes permiten asegurar una menor cantidad de errores en el caso de ISDB-S $\left(\mathrm{BER}=10^{-11}\right)$ que con DVB-S $\left(\mathrm{BER}=10^{-11}\right)$.

- La posibilidad de ajustar el factor de caída del filtro en el caso de DVB-S2, permite transportar una mayor cantidad de símbolos por Hertz disponible, comparado a los esquemas de roll-off fijo a 0.35 .

En el caso de análisis para sistemas de contribución con DVB-DSNG, DVB-S2 y la implementación TC8PSK del estándar ISDB-S, también se obtuvieron rendimientos de hasta $57 \%$ en volumen de datos transmitidos con DVB-S2 comparado con DVB-DSNG e ISDB-S. Esto utilizando umbrales de $\mathrm{C} / \mathrm{N}$ similares.

Para fines prácticos, ya sea que la limitante del canal sea la potencia o el ancho de banda, el estándar DVB-S2 balanceado correctamente tiene un desempeño en promedio 30\% superior que su antecesor DVB-S. Si a este mejor desempeño se le suma una mayor eficiencia de codificación a través del uso del estándar MPEG-4, se puede transportar hasta el doble de información con las especificaciones más recientes.

En el caso de la comparativa entre ISDB-S y los estándares DVB se puede mencionar que aunque el primero incorpora mayores herramientas en la adaptación 
al canal que DVB-S, no supera al estándar DVB-S2. La fortaleza de DVB-S2 radica en la robustez de su código de corrección de errores que en el caso de ISDB-S y DVB-S, es un mismo sistema con limitaciones ya evaluadas.

\section{Evaluación de enlaces}

Tomando en cuenta que el estándar DVB-S2 es el que ofrece las mejores características con base en la primera etapa del análisis, ahora es importante conocer sus már- genes de desempeño en enlaces por satélite en las bandas de frecuencia $\mathrm{Ku}$ y Ka.

También, se deben tomar en cuenta los beneficios que se obtendrían agregando un demodulador/modulador a bordo del satélite que convirtiera a los transpondedores en elementos regenerativos de señal basada en el estándar DVB-S2.

Nota: Los siguientes cálculos de enlace están basados en parámetros similares a los reales o en satélites supuestos en una misma posición orbital como referencia.

\section{Ejemplo 1}

En la tabla 5 se muestran los cálculos de una red para señal de televisión digital en satélite de servicio fijo con TP a saturación.

\begin{tabular}{|c|c|c|}
\hline Datos de la portadora & & \\
\hline Estándar & \multicolumn{2}{|c|}{ DVB-S2 } \\
\hline Symbol rate & \multicolumn{2}{|c|}{30000 KBaud } \\
\hline Modulación & \multicolumn{2}{|c|}{ 8PSK } \\
\hline F.E.C. & \multicolumn{2}{|c|}{$2 / 3$} \\
\hline Tasa de datos & \multicolumn{2}{|c|}{$58071.0 \mathrm{Kbps}$} \\
\hline Roll-off & \multicolumn{2}{|c|}{0.2} \\
\hline $\mathrm{Eb} / \mathrm{No}$ & \multicolumn{2}{|c|}{$3.75 \mathrm{~dB}$} \\
\hline BER & \multicolumn{2}{|c|}{$1 \mathrm{E}-7$} \\
\hline Ancho de banda requerido & \multicolumn{2}{|c|}{$36000.00 \mathrm{kHz}$} \\
\hline Ancho de banda asignado & \multicolumn{2}{|c|}{$36000.00 \mathrm{kHz}$} \\
\hline \multicolumn{3}{|l|}{ Datos del satélite } \\
\hline \multirow{3}{*}{$\begin{array}{l}\text { Posición del satélite } \\
\text { Ancho de banda del transpondedor }\end{array}$} & \multirow{2}{*}{\multicolumn{2}{|c|}{$\begin{array}{c}116.80^{\circ} \mathrm{W} \\
36.00 \mathrm{MHz}\end{array}$}} \\
\hline & & \\
\hline & Enlace ascendente & Enlace descendente \\
\hline Banda de operación & $14-14.5 \mathrm{GHz}$ & $11.7-12.2 \mathrm{GHz}$ \\
\hline Frecuencia central del TP & $14.04 \mathrm{GHz}$ & $11.74 \mathrm{GHz}$ \\
\hline Polaridad & Vertical & Horizontal \\
\hline Datos de estacion terrena & Transmisor & Receptor \\
\hline Localidad & Atlanta, Georgia, EU & México DF, México \\
\hline Latitud & $33.75^{\circ} \mathrm{N}$ & $19.40^{\circ} \mathrm{N}$ \\
\hline Longitud & $84.38^{\circ} \mathrm{W}$ & $99.15^{\circ} \mathrm{W}$ \\
\hline Disponibilidad ascendente & $99.80 \%$ & $99.80 \%$ \\
\hline Disponibilidad descendente & $99.80 \%$ & $99.80 \%$ \\
\hline Diámetro de antena & $7.00 \mathrm{~m}$ & $0.9 \mathrm{~m}$ \\
\hline Ganancia de antena Tx & $58.0 \mathrm{dBi}$ & $40.2 \mathrm{dBi}$ \\
\hline Ganancia de antena $R x$ & $56.5 \mathrm{dBi}$ & $38.7 \mathrm{dBi}$ \\
\hline Temperatura de la antena $\mathrm{Rx}$ & $30 \mathrm{~K}$ & $30 \mathrm{~K}$ \\
\hline Temperatura total del sistema & $190 \mathrm{~K}$ & $152 \mathrm{~K}$ \\
\hline Figura de meritosatélite $(\mathrm{G} / \mathrm{T})$ & $3.36 \mathrm{~dB} / \mathrm{K}$ & $3.88 \mathrm{~dB} / \mathrm{K}$ \\
\hline PIRE en saturación del Transpondedor & $51.02 \mathrm{dBW}$ & $50.58 \mathrm{dBW}$ \\
\hline
\end{tabular}




\section{Evaluación del enlace:}

Tabla 5. Televisión digital en servicio fijo

\begin{tabular}{|c|c|c|c|c|c|}
\hline Enlace ascendente & Cielo despejado & Lluvia ascendente & Lluvia descendente & $\begin{array}{l}\text { Lluvia ambos } \\
\text { lados }\end{array}$ & \\
\hline Azimut $\mathrm{E} / \mathrm{T}$ transmisora & 228.82 & 228.82 & 228.82 & 228.82 & $\circ$ \\
\hline Elevación E/T transmisora & 37.7 & 37.7 & 37.7 & 37.7 & $\circ$ \\
\hline Disponibilidad & 99.8 & 99.8 & 99.8 & 99.8 & $\%$ \\
\hline PIRE estación transmisora & 80 & 80 & 80 & 80 & dBW \\
\hline Perdidas por espacio libre & 206.98 & 206.98 & 206.98 & 206.98 & $\mathrm{~dB}$ \\
\hline Perdidas misceláneas & 1 & 1 & 1 & 1 & $\mathrm{~dB}$ \\
\hline Margen de lluvia & 0 & 3.97 & 0 & 3.97 & $\mathrm{~dB}$ \\
\hline Relación C/No ascendente & 103.98 & 100.01 & 103.98 & 100.01 & $\mathrm{dBHz}$ \\
\hline Relación C/N ascendente & 17.02 & 16.57 & 17.02 & 16.57 & $\mathrm{~dB}$ \\
\hline Enlace descendente & Cielo despejado & Lluvia ascendente & Lluvia descendente & $\begin{array}{l}\text { Lluvia ambos } \\
\text { lados }\end{array}$ & \\
\hline Azimut E/T receptora & 223.77 & 223.77 & 223.77 & 223.77 & $\circ$ \\
\hline Elevación E/T receptora & 59.62 & 59.62 & 59.62 & 59.62 & $\circ$ \\
\hline Disponibilidad & 99.8 & 99.8 & 99.8 & 99.8 & $\%$ \\
\hline P.I.R.E. en saturación transpondedor & 50.58 & 46.61 & 50.58 & 46.61 & $\mathrm{dBW}$ \\
\hline Perdidas por espacio libre & 205.1 & 205.1 & 205.1 & 205.1 & $\mathrm{~dB}$ \\
\hline Perdidas misceláneas & 1 & 1 & 1 & 1 & $\mathrm{~dB}$ \\
\hline Margen de lluvia & 0 & 0 & 1.83 & 1.83 & $\mathrm{~dB}$ \\
\hline G/T de la E/T receptora & 16.88 & 16.88 & 15.17 & 15.17 & $\mathrm{~dB} / \mathrm{K}$ \\
\hline Relación C/No descendente & 89.96 & 86 & 86.43 & 82.46 & $\mathrm{dBHz}$ \\
\hline Relación $\mathrm{C} / \mathrm{N}$ descendente & 14.2 & 10.35 & 10.77 & 6.86 & $\mathrm{~dB}$ \\
\hline Margen de enlace & Cielo despejado & Lluvia ascendente & Lluvia descendente & $\begin{array}{l}\text { Lluvia ambos } \\
\text { lados }\end{array}$ & \\
\hline Relación $\mathrm{C} / \mathrm{N}$ total del sistema & 12.38 & 9.42 & 9.85 & 6.42 & $\mathrm{~dB}$ \\
\hline Relación $\mathrm{C} / \mathrm{N}$ requerida & 5.83 & 5.83 & 5.83 & 5.83 & $\mathrm{~dB}$ \\
\hline Margen del enlace & 6.55 & 3.60 & 4.02 & 0.59 & $\mathrm{~dB}$ \\
\hline
\end{tabular}

Observamos que los márgenes de enlace para la disponibilidad de $99.8 \%$ en banda $\mathrm{Ku}$ con la red propuesta se cumplen en todos los casos para las localidades de transmisión y de recepción planteadas con los parámetros asignados inicialmente.

Para este caso no es muy práctico disminuir el diámetro de las antenas de recepción. En caso de que estos se redujeran a $0.7 \mathrm{~m}$ y no se variara algún otro parámetro se obtienen como resultados márgenes ne- gativos para el supuesto de lluvia en ambos lados del enlace.

En el caso de servicio fijo por satélite, se busca la mayor disponibilidad del enlace sin importar las condiciones climáticas, es por eso que pretender disminuir las dimensiones de las antenas no es un factor muy significativo. Con esta disponibilidad hay un estimado de que el enlace pueda estar inactivo unas 35 horas al año. 


\section{Ejemplo 2}

En la tabla 6 se muestran los cálculos de una red para senal de televisión digital en satélite de servicio broadcast.

\begin{tabular}{|c|c|c|}
\hline Datos de la portadora & & \\
\hline Estándar & \multicolumn{2}{|c|}{ DVB-S2 } \\
\hline Symbol rate & \multicolumn{2}{|c|}{30000 KBaud } \\
\hline Modulación & \multicolumn{2}{|c|}{ 8PSK } \\
\hline F.E.C. & \multicolumn{2}{|c|}{$2 / 3$} \\
\hline Tasa de datos & \multicolumn{2}{|c|}{$58071.0 \mathrm{Kbps}$} \\
\hline Roll-off & \multicolumn{2}{|c|}{0.2} \\
\hline $\mathrm{Eb} / \mathrm{No}$ & \multicolumn{2}{|c|}{$3.75 \mathrm{~dB}$} \\
\hline BER & \multicolumn{2}{|c|}{$1 \mathrm{E}-7$} \\
\hline Ancho de banda requerido & \multicolumn{2}{|c|}{$36000.00 \mathrm{kHz}$} \\
\hline Ancho de banda asignado & \multicolumn{2}{|c|}{$36000.00 \mathrm{kHz}$} \\
\hline \multicolumn{3}{|l|}{ Datos del satélite } \\
\hline Posición del satélite & \multicolumn{2}{|c|}{$116.80^{\circ} \mathrm{W}$} \\
\hline Ancho de banda del transpondedor & \multicolumn{2}{|c|}{$36.00 \mathrm{MHz}$} \\
\hline & Enlace ascendente & Enlace descendente \\
\hline Banda de operación & $17.8-18.3 \mathrm{GHz}$ & $12.2-12.7 \mathrm{GHz}$ \\
\hline Frecuencia central del TP & $17.84 \mathrm{GHz}$ & $12.24 \mathrm{GHz}$ \\
\hline polaridad & LHCP & RHCP \\
\hline Datos de estacion terrena & Transmisor & Receptor \\
\hline Localidad & Atlanta, Georgia, EU & México DF, México \\
\hline Latitud & $33.75^{\circ} \mathrm{N}$ & $19.40^{\circ} \mathrm{N}$ \\
\hline Longitud & $84.38^{\circ} \mathrm{W}$ & $99.15^{\circ} \mathrm{W}$ \\
\hline Disponibilidad ascendente & $99.70 \%$ & $99.70 \%$ \\
\hline Disponibilidad descendente & $99.70 \%$ & $99.70 \%$ \\
\hline Diámetro de antena & $7.00 \mathrm{~m}$ & $0.7 \mathrm{~m}$ \\
\hline Ganancia de antena Tx & $60.12 \mathrm{dBi}$ & $40.12 \mathrm{dBi}$ \\
\hline Ganancia de antena $R x$ & $56.85 \mathrm{dBi}$ & $36.85 \mathrm{dBi}$ \\
\hline Temperatura total del sistema & $190 \mathrm{~K}$ & $152 \mathrm{~K}$ \\
\hline Figura de merito satélite (G/T) & $3.36 \mathrm{~dB} / \mathrm{K}$ & $3.88 \mathrm{~dB} / \mathrm{K}$ \\
\hline PIRE en saturación del transpondedor & $51.02 \mathrm{dBW}$ & $50.58 \mathrm{dBW}$ \\
\hline
\end{tabular}




\section{Evaluación del enlace:}

Tabla 6. Televisión digital en servicio broadcast

\begin{tabular}{|c|c|c|c|c|c|}
\hline Enlace ascendente & Cielo despejado & Lluvia ascendente & Lluvia descendente & $\begin{array}{l}\text { Lluvia ambos } \\
\text { lados }\end{array}$ & \\
\hline Azimut $\mathrm{E} / \mathrm{T}$ transmisora & 228.82 & 228.82 & 228.82 & 228.82 & $\circ$ \\
\hline Elevación E/T Transmisora & 37.7 & 37.7 & 37.7 & 37.7 & $\circ$ \\
\hline Disponibilidad & 99.7 & 99.7 & 99.7 & 99.7 & $\%$ \\
\hline PIRE estación transmisora & 80 & 80 & 80 & 80 & dBW \\
\hline Perdidas por espacio libre & 209.06 & 209.06 & 209.06 & 209.06 & $\mathrm{~dB}$ \\
\hline Perdidas misceláneas & 1 & 1 & 1 & 1 & $\mathrm{~dB}$ \\
\hline Margen de lluvia & 0 & 5.6 & 0 & 5.6 & $\mathrm{~dB}$ \\
\hline Relación C/No ascendente & 101.9 & 96.3 & 101.9 & 96.3 & $\mathrm{dBHz}$ \\
\hline Relación C/N ascendente & 26.33 & 20.74 & 26.33 & 20.74 & $\mathrm{~dB}$ \\
\hline Enlace descendente & Cielo despejado & Lluvia ascendente & Lluvia descendente & $\begin{array}{l}\text { Lluvia ambos } \\
\text { lados }\end{array}$ & \\
\hline Azimut E/T receptora & 223.77 & 223.77 & 223.77 & 223.77 & $\circ$ \\
\hline Elevación E/T receptora & 59.62 & 59.62 & 59.62 & 59.62 & $\circ$ \\
\hline Disponibilidad & 99.7 & 99.7 & 99.7 & 99.7 & $\%$ \\
\hline Perdidas por espacio libre & 205.46 & 205.46 & 205.46 & 205.46 & dBW \\
\hline P.I.R.E. en saturación transpondedor & 50.58 & 44.98 & 50.58 & 44.98 & $\mathrm{~dB}$ \\
\hline Perdidas misceláneas & 1 & 1 & 1 & 1 & $\mathrm{~dB}$ \\
\hline Margen de lluvia & 0 & 0 & 1.55 & 1.55 & $\mathrm{~dB}$ \\
\hline G/T de la E/T receptora & 15.03 & 15.03 & 13.51 & 13.51 & $\mathrm{~dB} / \mathrm{K}$ \\
\hline Relación C/No descendente & 87.75 & 82.15 & 84.68 & 79.09 & $\mathrm{dBHz}$ \\
\hline Relación C/N descendente & 12.19 & 6.59 & 9.12 & 3.52 & $\mathrm{~dB}$ \\
\hline Margen de enlace & Cielo despejado & Lluvia ascendente & Lluvia descendente & $\begin{array}{l}\text { Lluvia ambos } \\
\text { lados }\end{array}$ & \\
\hline Relación $\mathrm{C} / \mathrm{N}$ total del sistema & 12.03 & 6.43 & 9.04 & 3.44 & $\mathrm{~dB}$ \\
\hline Relación $\mathrm{C} / \mathrm{N}$ requerida & 5.83 & 5.83 & 5.83 & 5.83 & $\mathrm{~dB}$ \\
\hline Margen del enlace & 6.2 & 0.6 & 3.21 & -2.39 & $\mathrm{~dB}$ \\
\hline
\end{tabular}


Hay un gran número de factores que intervienen en el cálculo de un enlace. Sin embargo, en las simulaciones hechas se observa que en un enlace por satélite para servicios de broadcast se requiere mayor potencia en los amplificadores del satélite para alcanzar márgenes similares a los enlaces para servicio fijo. Hay que tomar en cuenta que las frecuencias de los enlaces ascendentes y descendentes sufren de mayor atenuación, por lo cual es muy importante el criterio de la potencia.

Al ser satélites de mayor potencia que los de servicio fijo, en la recepción de las señales de broadcast se pueden evaluar antenas de menor diámetro a la recepción. De igual manera, se puede evaluar un enlace para una disponibilidad menor, pero esto en detrimento del servicio ofrecido a los suscriptores. Para los valores de disponibilidad supuestos, el estimado anual de horas en que el servicio estará caído es 52.5. A medida que la frecuencia aumenta, es evidente que es más complicado obtener márgenes positivos. Es por esto que se debe de sacrificar disponibilidad en algunos casos.

\section{Ejemplo 3}

En la tabla 7 se muestran los cálculos de una red para señal de televisión digital en satélite de servicio broadcast en banda $\mathrm{Ka}^{1}$.

\begin{tabular}{|c|c|c|}
\hline \multicolumn{3}{|l|}{ Datos de la portadora } \\
\hline Estándar & \multicolumn{2}{|c|}{ DVB-S2 } \\
\hline Symbol rate & \multicolumn{2}{|c|}{30000 KBaud } \\
\hline Modulación & \multicolumn{2}{|c|}{ 8PSK } \\
\hline F.E.C. & \multicolumn{2}{|c|}{$2 / 3$} \\
\hline Tasa de datos & \multicolumn{2}{|c|}{$58071.0 \mathrm{kbps}$} \\
\hline Roll-off & \multicolumn{2}{|c|}{0.2} \\
\hline $\mathrm{Eb} / \mathrm{No}$ & \multicolumn{2}{|c|}{$3.75 \mathrm{~dB}$} \\
\hline BER & \multicolumn{2}{|c|}{$1 \mathrm{E}-7$} \\
\hline Ancho de banda requerido & \multicolumn{2}{|c|}{$36000.00 \mathrm{kHz}$} \\
\hline Ancho de banda asignado & \multicolumn{2}{|c|}{$36000.00 \mathrm{kHz} \quad 1$} \\
\hline \multicolumn{3}{|l|}{ Datos del satélite } \\
\hline \multirow[t]{2}{*}{ Posición del satélite } & \multicolumn{2}{|c|}{$116.8^{\circ} \mathrm{W}$} \\
\hline & Enlace ascendente & Enlace descendente \\
\hline Banda de operación & $29.5-30 \mathrm{GHz}$ & $19.7-20.2 \mathrm{GHz}$ \\
\hline Frecuencia central del TP & $29.7 \mathrm{GHz}$ & $19.9 \mathrm{GHz}$ \\
\hline Polaridad & Horizontal & Vertical \\
\hline Datos de estacion terrena & Transmisor & Receptor \\
\hline Localidad & Atlanta, Georgia, EU & México DF, México \\
\hline Latitud & $33.75^{\circ} \mathrm{N}$ & $19.40^{\circ} \mathrm{N}$ \\
\hline Longitud & $84.38^{\circ} \mathrm{W}$ & $99.15^{\circ} \mathrm{W}$ \\
\hline Disponibilidad ascendente & $99.00 \%$ & $99.00 \%$ \\
\hline Disponibilidad descendente & $99.00 \%$ & $99.00 \%$ \\
\hline Diámetro de antena & $7.00 \mathrm{~m}$ & $0.70 \mathrm{~m}$ \\
\hline Ganancia de antena Tx & $64.55 \mathrm{dBi}$ & $44.55 \mathrm{dBi}$ \\
\hline Ganancia de antena Rx & $61.07 \mathrm{dBi}$ & $41.07 \mathrm{dBi}$ \\
\hline Temperatura total del sistema & $350 \mathrm{~K}$ & $300 \mathrm{~K}$ \\
\hline Figura de merito satélite (G/T) & $16.0 \mathrm{~dB} / \mathrm{K}$ & $16.0 \mathrm{~dB} / \mathrm{K}$ \\
\hline PIRE en saturación del transpondedor & 54 & $54 \mathrm{Dbw}$ \\
\hline
\end{tabular}

1 Descartando ambiente de interferencia por inducciones entre satélites adyacentes, polarización cruzada e intermodulación 


\section{Evaluación del enlace:}

Tabla 7. Televisión digital en servicio broadcast en banda Ka

\begin{tabular}{|c|c|c|c|c|c|}
\hline Enlace ascendente & Cielo despejado & Lluvia ascendente & Lluvia descendente & $\begin{array}{l}\text { Lluvia ambos } \\
\text { lados }\end{array}$ & \\
\hline Azimut $\mathrm{E} / \mathrm{T}$ transmisora & 228.82 & 228.82 & 228.82 & 228.82 & $\circ$ \\
\hline Elevación E/T transmisora & 37.7 & 37.7 & 37.7 & 37.7 & $\circ$ \\
\hline Disponibilidad & 99 & 99 & 99 & 99 & $\%$ \\
\hline PIRE estación transmisora & 80 & 80 & 80 & 80 & dBW \\
\hline Perdidas por espacio libre & 213.49 & 213.49 & 213.49 & 213.49 & $\mathrm{~dB}$ \\
\hline Perdidas misceláneas & 1 & 1 & 1 & 1 & $\mathrm{~dB}$ \\
\hline Margen de lluvia & 0 & 5.57 & 0 & 5.57 & $\mathrm{~dB}$ \\
\hline Relación C/No ascendente & 110.11 & 104.53 & 110.11 & 104.53 & $\mathrm{dBHz}$ \\
\hline Relación $\mathrm{C} / \mathrm{N}$ ascendente & 34.55 & 28.97 & 34.55 & 28.97 & $\mathrm{~dB}$ \\
\hline Enlace descendente & Cielo despejado & Lluvia ascendente & Lluvia descendente & $\begin{array}{l}\text { Lluvia ambos } \\
\text { lados }\end{array}$ & \\
\hline Azimut E/T receptora & 223.77 & 223.77 & 223.77 & 223.77 & $\circ$ \\
\hline Elevación E/T receptora & 59.62 & 59.62 & 59.62 & 59.62 & $\circ$ \\
\hline Disponibilidad & 99 & 99 & 99 & 99 & $\%$ \\
\hline Perdidas por espacio libre & 209.68 & 209.68 & 209.68 & 209.68 & dBW \\
\hline P.I.R.E. en saturación transpondedor & 54 & 48.43 & 54 & 48.43 & $\mathrm{~dB}$ \\
\hline Perdidas misceláneas & 1 & 1 & 1 & 1 & $\mathrm{~dB}$ \\
\hline Margen de lluvia & 0 & 0 & 1.6 & 1.6 & $\mathrm{~dB}$ \\
\hline G/T de la E/T receptora & 16.6 & 16.6 & 17.44 & 17.44 & $\mathrm{~dB} / \mathrm{K}$ \\
\hline Relación C/No descendente & 88.52 & 82.94 & 87.76 & 82.18 & $\mathrm{dBHz}$ \\
\hline Relación $\mathrm{C} / \mathrm{N}$ descendente & 12.95 & 7.38 & 12.2 & 6.62 & $\mathrm{~dB}$ \\
\hline Margen de enlace & Cielo despejado & Lluvia ascendente & Lluvia descendente & $\begin{array}{l}\text { Lluvia ambos } \\
\text { lados }\end{array}$ & \\
\hline Relación C/N total del Sistema & 12.92 & 7.35 & 12.17 & 6.6 & $\mathrm{~dB}$ \\
\hline Relación $\mathrm{C} / \mathrm{N}$ requerida & 5.83 & 5.83 & 5.83 & 5.83 & $\mathrm{~dB}$ \\
\hline Margen del enlace & 7.1 & 1.52 & 6.34 & 0.77 & $\mathrm{~dB}$ \\
\hline
\end{tabular}

Al evaluar enlaces en banda Ka para televisión es cuando se aprecia la gran importancia de algunos parámetros, tanto en el segmento espacial como en el satelital. La atenuación que se llega a sufrir en esta banda debe ser contrarrestada con varios elementos dentro del enlace. El hecho de usar haces concentrados o puntuales en áreas menores se vuelve el factor primordial en este caso. De lo contrario, sería muy difícil construir equipamiento que fuera capaz de establecer un enlace.
Tomando en cuenta lo ya dicho acerca de la disponibilidad, en un enlace con estas características hay un aproximado de 174 horas (7.2 días) en el año que el servicio no se lograría. Debido a esto, los servicios en banda Ka son configuraciones en que es tolerable la pérdida o falta de información por intervalos mayores de tiempo comparado con otras bandas. La alternativa de un enlace regenerativo trae consigo importantes mejoras en la disponibilidad y márgenes del enlace. 


\section{Ejemplo 4}

En la tabla 8 se muestran los cálculos de una red para señal de televisión digital en satélite de servicio broadcast con transpondedor regenerativo en banda Ka.

\begin{tabular}{|c|c|c|}
\hline Datos de la portadora & & \\
\hline Estándar & \multicolumn{2}{|c|}{ DVB-S2 } \\
\hline Symbol rate & \multicolumn{2}{|c|}{30000 KBaud } \\
\hline Modulación & \multicolumn{2}{|c|}{ 8PSK } \\
\hline F.E.C. & \multicolumn{2}{|c|}{$2 / 3$} \\
\hline Tasa De Datos & \multicolumn{2}{|c|}{$58071.0 \mathrm{Kbps}$} \\
\hline Roll-off & \multicolumn{2}{|c|}{0.2} \\
\hline $\mathrm{Eb} / \mathrm{No}$ & \multicolumn{2}{|c|}{$3.75 \mathrm{~dB}$} \\
\hline BER & \multicolumn{2}{|c|}{$2 \mathrm{E}-7$} \\
\hline Ancho de banda requerido & \multicolumn{2}{|c|}{$36000.00 \mathrm{kHz}$} \\
\hline Ancho de banda asignado & \multicolumn{2}{|c|}{$36000.00 \mathrm{kHz}$} \\
\hline \multicolumn{3}{|l|}{ Datos del satélite } \\
\hline \multirow[t]{2}{*}{ Posición del satélite } & \multicolumn{2}{|c|}{$116.80^{\circ} \mathrm{W}$} \\
\hline & Enlace ascendente & Enlace descendente \\
\hline Banda de operación & 29.5-30 GHz & $19.7-20.2 \mathrm{GHz}$ \\
\hline Frecuencia central del TP & $29.7 \mathrm{GHz}$ & $19.9 \mathrm{GHz}$ \\
\hline Polaridad & Horizontal & Vertical \\
\hline Datos de estacion terrena & Transmisor & Receptor \\
\hline Localidad & Atlanta, Georgia, EU & México DF, México \\
\hline Latitud & $33.75^{\circ} \mathrm{N}$ & $19.40^{\circ} \mathrm{N}$ \\
\hline Longitud & $84.38^{\circ} \mathrm{W}$ & $99.15^{\circ} \mathrm{W}$ \\
\hline Disponibilidad ascendente & $99.00 \%$ & $99.00 \%$ \\
\hline Disponibilidad descendente & $99.00 \%$ & $99.00 \%$ \\
\hline Diámetro de antena & $7.00 \mathrm{~m}$ & $0.60 \mathrm{~m}$ \\
\hline Ganancia de antena Tx & $64.55 \mathrm{dBi}$ & $43.21 \mathrm{dBi}$ \\
\hline Ganancia de antena $R x$ & $61.07 \mathrm{dBi}$ & $39.73 \mathrm{dBi}$ \\
\hline Temperatura total del sistema & $350 \mathrm{~K}$ & $300 \mathrm{~K}$ \\
\hline Figura de merito satélite $(\mathrm{G} / \mathrm{T})$ & $16.0 \mathrm{~dB} / \mathrm{K}$ & $16.0 \mathrm{~dB} / \mathrm{K}$ \\
\hline PIRE en saturación del transpondedor & $54 \mathrm{dBW}$ & $54 \mathrm{dBW}$ \\
\hline
\end{tabular}




\section{Evaluación del enlace:}

Tabla 8. Televisión digital en servicio broadcast con transpondedor regenerativo en banda Ka

\begin{tabular}{|c|c|c|c|c|c|}
\hline Enlace ascendente & Cielo despejado & Lluvia ascendente & Lluvia descendente & Lluvia ambos lados & \\
\hline Azimut $\mathrm{E} / \mathrm{T}$ transmisora & 228.82 & 228.82 & 228.82 & 228.82 & $\circ$ \\
\hline Elevación E/T transmisora & 37.7 & 37.7 & 37.7 & 37.7 & $\circ$ \\
\hline Disponibilidad & 99.7 & 99.7 & 99.7 & 99.7 & $\%$ \\
\hline PIRE estación transmisora & 75 & 75 & 75 & 75 & $\mathrm{dBW}$ \\
\hline Perdidas por espacio libre & 213.49 & 213.49 & 213.49 & 213.49 & $\mathrm{~dB}$ \\
\hline Perdidas misceláneas & 1 & 1 & 1 & 1 & $\mathrm{~dB}$ \\
\hline Margen de lluvia & 0 & 14.69 & 0 & 14.69 & $\mathrm{~dB}$ \\
\hline Relación C/No ascendente & 101.11 & 86.42 & 101.11 & 86.42 & $\mathrm{dBHz}$ \\
\hline Relación $\mathrm{C} / \mathrm{N}$ ascendente & 25.55 & 10.85 & 25.55 & 10.85 & $\mathrm{~dB}$ \\
\hline Enlace descendente & Cielo despejado & Lluvia ascendente & Lluvia descendente & Lluvia ambos lados & \\
\hline Azimut E/T receptora & 223.77 & 223.77 & 223.77 & 223.77 & $\circ$ \\
\hline Elevación E/T receptora & 59.62 & 59.62 & 59.62 & 59.62 & $\circ$ \\
\hline Disponibilidad & 99.7 & 99.7 & 99.7 & 99.7 & $\%$ \\
\hline Perdidas por espacio libre & 209.68 & 209.68 & 209.68 & 209.68 & dBW \\
\hline P.I.R.E. en saturación transpondedor & 54 & 54 & 54 & 54 & $\mathrm{~dB}$ \\
\hline Perdidas misceláneas & 1 & 1 & 1 & 1 & $\mathrm{~dB}$ \\
\hline Margen de lluvia & 0 & 0 & 4.98 & 4.98 & $\mathrm{~dB}$ \\
\hline G/T de la E/T receptora & 15.26 & 15.26 & 14.87 & 14.87 & $\mathrm{~dB} / \mathrm{K}$ \\
\hline Relación C/No descendente & 87.18 & 87.18 & 81.81 & 81.81 & $\mathrm{dBHz}$ \\
\hline Relación $\mathrm{C} / \mathrm{N}$ descendente & 11.61 & 11.61 & 6.24 & 6.24 & $\mathrm{~dB}$ \\
\hline Margen de enlace & Cielo despejado & Lluvia ascendente & Lluvia descendente & Lluvia ambos lados & \\
\hline Relación $\mathrm{C} / \mathrm{N}$ requerida & 5.83 & 5.83 & 5.83 & 5.83 & $\mathrm{~dB}$ \\
\hline Margen del enlace ascendente & 19.72 & 5.03 & 19.72 & 5.03 & $\mathrm{~dB}$ \\
\hline Margen del enlace descendente & 5.79 & 5.79 & 0.42 & 0.42 & $\mathrm{~dB}$ \\
\hline
\end{tabular}

Tomando las mismas características del ejemplo número 4, se observa que el uso de un transpondedor regenerativo en banda Ka permite obtener márgenes positivos con menores recursos en la transmisión de Tierra. El enlace va a funcionar siempre y cuando los niveles de $\mathrm{C} / \mathrm{N}$ en cada trayectoria sean los mínimos que aseguren el Eb/N0 de 3.75dB a la recepción.

Hay que tomar en cuenta que no obstante los márgenes positivos, se agrega complejidad al diseño del satélite y, por otro lado la tasa de errores se puede llegar a duplicar en sistemas mal balanceados.

En la banda Ka se tienen ganancias mayores de las antenas en razón de $3 \mathrm{~dB}$, con respecto a la banda $\mathrm{Ku}$. Sin embargo, la ganancia obtenida es contrarrestada con los efectos diversos de atenuación que son mucho más extremos para esta banda. En el ejemplo mostrado, se observa que en Atlanta la atenuación por efecto de la lluvia en banda Ka (29.7GHz) para una disponibilidad 


\begin{tabular}{cccc}
\hline Servicio & PIREasc $(\mathrm{dBw})$ & Antena Receptora $(\mathrm{cm})$ & Margen del enlace \\
\hline Servicio Fijo & 80 & 0.90 & 0.59 \\
Radiodifusión Ku & 80 & 0.70 & -2.39 \\
Radiodifusión Ka & 80 & 0.70 & 0.77 \\
$\begin{array}{l}\text { Radiodifusión Ka } \\
\text { (TP Regenerativo) }\end{array}$ & 75 & 0.60 & 0.42 \\
\hline
\end{tabular}

Tabla 9. Comparaciones en Ku y Ka

de $99.7 \%$ es de $14.69 \mathrm{~dB}$, este valor de atenuación es 8 veces mayor a la presente en la misma localidad a 17 $\mathrm{GHz}(5.6 \mathrm{~dB})$. Para el enlace descendente, la atenuación en banda Ka resultó 2 veces mayor a la de Ku.

En la parte del segmento satelital, la realización de simulaciones y cálculos de enlace permite conocer los parámetros necesarios de la señales para que la comunicación se pueda llevar a cabo. Evaluando la afectación de la lluvia y las pérdidas por propagación de las ondas en el espacio libre se observaron las dificultades que enfrentan los analistas de redes satelitales para balancear enlaces de banda Ka. Hay que tomar en cuenta, además, los siguientes factores para el uso de la banda Ka:

Las antenas de los satélites ofrecen mayores ganancias y patrones de radiación más estrechos.

El uso de haces puntuales permite un mejor reúso de frecuencias, pero requiere un mejor alineamiento de las antenas.

Las líneas de trasmisión son de dimensiones más críticas. La pérdida es mayor en estos componentes y su fragilidad también.

Los elementos activos tienen un desempeño más pobre a nivel de RF que a frecuencias menores (potencia de salida, eficiencia, control de características, etcétera).

Considerando lo último, tanto en el diseño de la carga útil del satélite como en el diseño de las estaciones terrenas, la posibilidad de implementar enlaces en banda Ka se ha convertido en una realidad y ha penetrado al mercado gracias a las apuestas de los grandes controladores satelitales como SES, Intelsat, Eutelsat y Telesat.

La tabla 9 muestra un resumen general de los resultados para las bandas $\mathrm{Ku}, \mathrm{Ka}$ y Ka con TP regenerativo.

\section{Conclusiones}

Se realizó un análisis del estándar DVB-S2 con base en los parámetros definidos por dicho estándar. Una vez demostrada la superioridad operativa de éste, se realizaron análisis de enlaces bajo el estándar. Con dichos análisis se determinaron los márgenes y niveles de disponibilidad necesarios para un cálculo que involu- cra dos localidades. Con ayuda de las recomendaciones de la UIT y herramientas de software se llevó a cabo el procedimiento de cálculo en función de la frecuencia, disponibilidad, polarización del enlace, entre otros elementos.

El estándar DVB-S2 es actualmente el conjunto de protocolos de transporte más eficiente para el flujo de programas de televisión por satélite, en términos de ancho de banda y potencia. A través del estándar se pueden transmitir datos con video y audio de alta calidad. El uso de tramas especiales y modulaciones variables también permite priorizar algunos datos y hace factible el transporte de datos codificados con diversos estándares o de diferente naturaleza, sin embargo, habrá que esperar a la evolución del sistema ABS-S en términos de los costos de los equipos.

En la banda Ka (transpondedor transparente), se obtienen resultados similares que en la banda $\mathrm{Ku}$, pero con una disponibilidad menor.

Para la banda Ka con transpondedor regenerativo, con menor potencia y diámetro de antena a la recepción, todavía se pueden obtener márgenes positivos en el enlace.

\section{Referencias}

Framing Structure, Channel Coding and Modulation for 11/12 GHz Satellite Services, European Norm EN 300 421, agosto de 1997.

Framing Structure, Channel Coding and Modulation for DSNG and Other Contribution Applications by Satellite, European Norm EN 301 210, marzo de 1999.

Morello A., Mignone V. DVB-S2: The Second Generation Standard for Satellite Broad-Band Services. Proceedings of the IEEE, volumen 94 (número 1), enero 2006: 18.

Second Generation Framing Structure, Channel Coding and Modulation Systems for Broadcasting, Interactive Services, News Gathering and Other Broad-Band Satellite Applications (DVB-S2), European Norm EN 302 307, agosto de 2009.

Saito T., et al. ISDB-S: Satellite Transmission System for Advanced Multimedia Services Provided by Integrated Services Digital 
Broadcasting. NHK STRL Bulletin Broadcast Technology, (número 5) 2000 [en linea] [fecha de consulta 4 de agosto de 2012]. Disponible en: http://www.nhk.or.jp/strl/publica/bt/en/pa0005. html

Shi Y. et al. A New Generation Satellite Broadcasting System In China, en: WiCOM ' $084^{\text {th }}$ International Conference, Wireless Communications, Networking and Mobile Computing, IEEE, 12-14 de octubre 2008, p 3.

UIT-R, BO.1516 (01.12). Sistemas de televisión digital multiprograma para utilización por satélites que funcionan en la gama de frecuencias 11/12 GHz, enero de 2012.

UIT-R, SNG.770-1 (09/94). Procedimientos operativos uniformes para el periodismo electrónico por satélite (SNG), septiembre de 1994.

\section{Bibliografía}

A/81: ATSC Direct-to-Home Satellite Broadcast Standard, Advanced Television Systems Committee, Washington, DC, 2003.

Benoit H. Digital Television Satellite, Cable, Terrestrial, IPTV, Mobile TV in the DVB Framework, 3a ed., Focal Press, 2006, pp. 173219.

Breynaert D., D'Oreye M. Analysis of the Bandwidth Efficiency of DVB-S2 in a Typical Data Distribution Network, Beijing, CCBN2005, marzo 2005, p. 5.

Dulac S, Godwin J, Satellite Direct-to-Home. Proceedings of the IEEE, volumen 94 (número 1), enero 2006.

Katoh H., Transmission System for ISDB-S. Proceedings of the IEEE, volumen 94 (número 1), enero 2006.
Neri R. Cálculos de enlace en RF en su comunicaciones por satélite, 1a ed., México, Thomson, 2003, pp. 293-362.

The International Telecommunications Union, Handbook on Satellite Communications, 3a ed., Wiley, 2002, pp. 71-81.

UIT-R, BO.1408-1 (04/02). Sistema de transmisión para servicios multimedio avanzados de la radiodifusión digital de servicios integrados en un canal de radiodifusión por satélite, abril de 2012.

UIT-R, P.618.10 (10/09). Datos de propagación y métodos de predicción necesarios para el diseño de sistemas de telecomunicación Tierra-espacio, octubre de 2009.

\section{Este artículo se cita: \\ Citación estilo Chicago}

Landeros-Ayala, Salvador, Sergio A. Chávez-Cárdenas, Juan C. González-Sánchez. Análisis de la eficiencia de los estándares de transmisión de televisión digital por satélite en las bandas Ku y Ka. Ingeniería Investigación y Tecnología, XIV, 03 (2013): 335-353.

\section{Citación estilo ISO 690}

Landeros-Ayala S., Chávez-Cárdenas S.A., González-Sánchez J.C. Análisis de la eficiencia de los estándares de transmisión de televisión digital por satélite en las bandas Ku y Ka. Ingeniería Investigación y Tecnología, volumen XIV (número 3), julio-septiembre 2013: 335-353.

\section{Semblanza de los autores}

Salvador Landeros-Ayala. Es ingeniero mecánico electricista en el área de telecomunicaciones por la Universidad Nacional Autónoma de México (UNAM). Obtuvo el grado de maestría en ciencias por la Universidad de Pennsylvania, Estados Unidos y el de doctor en ingeniería por la UNAM, ambos en ingeniería eléctrica. Es profesor titular C de tiempo completo en la Facultad de Ingeniería de la UNAM y ha sido profesor visitante en la Universidad Politécnica de Madrid. Ha desempeñado diversos cargos en la Facultad de Ingeniería de la UNAM, así como en la industria del sector de las telecomunicaciones, incluyendo la Dirección del Sistema de Satélites Mexicanos. Ha publicado 40 artículos en revistas nacionales e internacionales y ha impartido conferencias en Estados Unidos, Europa, y América Latina. Ha sido editor asociado y revisor en revistas técnicas. Ha sido presidente y vicepresidente de varias asociaciones de ingenieros y ha recibido reconocimientos por sus contribuciones al desarrollo de las telecomunicaciones en México. Es académico de la Academia de Ingeniería de México.

Sergio A. Chávez-Cárdenas. Egresó de la carrera de ingeniería en telecomunicaciones de la Facultad de Ingeniería de la UNAM (2007-2011) con la tesis: Perspectivas tecnológicas en sistemas de televisión digital por satélite. Actualmente trabaja en Satélites Mexicanos SA de CV como analista de acceso y tráfico satelital.

Juan C. González-Sánchez. Egresó de la carrera de ingeniería en telecomunicaciones de la Universidad Nacional Autónoma de México (UNAM) en 2010 con el trabajo de tesis: Perspectivas tecnológicas en sistemas de television digital por satélite. Trabajó en Ericsson como service engineer assessed. Actualmente labora en telefónica como ingeniero en RF y transmisión. 